\title{
SUBARACHNOID BLOCK IN A PATIENT WITH EBSTEIN'S ANOMALY
}

\author{
Usha Devi R¹, Vasantha Kumar K. R², Vasundhara V. M³ , Aditi Prabhu4
}

\section{HOW TO CITE THIS ARTICLE:}

Usha Devi R, Vasantha Kumar K. R, Vasundhara V. M, Aditi Prabhu. "Subarachnoid Block in a Patient with Ebstein's Anomaly". Journal of Evolution of Medical and Dental Sciences 2015; Vol. 4, Issue 82, October 12; Page: 14377-14383, DOI: 10.14260/jemds/2015/2045

ABSTRACT: BACKGROUND AND OBJECTIVES: Ebstein's anomaly is one of the rare congenital heart conditions that occur due an abnormal development of the tricuspid valve with "atrialization" of the right ventricle, leading to a small effective distal portion causing poor ventricular function. It may be associated with other cardiac malformations, rhythm disturbances or even a failing heart. When these patients report for surgery, the anaesthetic considerations are serious and reports about the use of central neuraxial blockade for the same is rare. Hence this study aims to provide some knowledge and information on the use of subarachnoid block in a case of Ebstein's anomaly posted for haemorrhoidectomy. PRESENTATION: DIAGNOSIS AND MANAGEMENT: A 48year old female patient with external and internal haemorrhoids was posted for haemorrhoidectomy. She was a known hypertensive with grade 1 hypertensive retinopathy on fundoscopy and was on treatment for the same. ECG showed a WPW syndrome pattern and chest radiograph showed mild cardiomegaly. 2D echocardiography revealed a dilated right atrium and right ventricle, with apical displacement of septal tricuspid leaflet and Ebstein's anomaly. There was moderate tricuspid regurgitation. Biventricular function was good with intact septum. The ejection fraction was $65 \%$. The patient was given a low subarachnoid block in anti-trendelenberg position in the L3-L4 interspace with a combination of bupivacaine $0.5 \%$ heavy $4.5 \mathrm{mg}$ and fentanyl $15 \mathrm{mcg}$ (Total volume of $1.2 \mathrm{ml}$ ). There was good anaesthetization with sensory and motor blockade of the saddle area. The patient was haemodynamically stable, without hypotension, rhythm disturbances or any other untoward incident throughout the procedure and in the postoperative period. CONCLUSION: Very few reports are available on the use of subarachnoid block in patients with Ebstein's anomaly. The feared drawback with its use is the occurrence of precipitous hypotension, leading to worsening of right to left shunt when it is present. Though our patient had an associated Wolff Parkinson White syndrome, she had no additional serious conditions like septal defects with reversal of flow or cardiac failure. Hence, we considered giving a low dose saddle block in view of the site of surgery and to minimize the sympathetic blockade.

KEYWORDS: Ebstein's anomaly, Subarachnoid block anaesthesia, Haemorrhoidectomy.

INTRODUCTION: Ebstein's anomaly is a rare congenital heart disease which was first described by Wilhelm Ebstein in 1866.(1) It is due to an incomplete delamination of the embryonic tricuspid valve, resulting in an atypically displaced valve tissue leading to congenital tricuspid insufficiency. The severity of the hemodynamic derangements in patients with Ebstein's anomaly depends on the degree of displacement and the functional status of the tricuspid valve leaflets. As a result, the clinical presentation varies from congestive heart failure in neonates to the absence of symptoms in adults, in whom the anomaly may be an incidental discovery.(2) In our instance, the patient was diagnosed incidentally as having Ebstein's anomaly and we could successfully manage her haemorrhoidectomy with subarachnoid block. 


\section{ORIGINAL ARTICLE}

PRESENTATION: DIAGNOSIS AND MANAGEMENT: A 48year old female patient presented to our pre-anaesthetic clinic with external and internal haemorrhoids and was posted for haemorrhoidectomy. She was a known hypertensive since one year with grade I hypertensive retinopathy on fundoscopy. She was on regular medications for the same with tablet amlodipine $5 \mathrm{mg}$ and tablet atenolol 50mg once a day. She had good metabolic equivalents of 6 to 8 and gave a history of two previous normal deliveries and subsequent tubal sterilization 14 years ago under subarachnoid block without any complication. On general physical examination her vital parameters were within normal limits and airway assessment revealed a Mallampatti classification of grade III. She also had short neck and buck teeth, and difficult intubation was anticipated.

All her routine blood investigations were within normal limits. ECG showed WPW syndrome pattern. The chest radiograph showed mild cardiomegaly with the cardiothoracic ratio being less than 0.65. 2D echocardiography revealed a dilated right atrium and right ventricle, with apical displacement of septal tricuspid leaflet and Ebstein's anomaly. There was moderate tricuspid regurgitation with right ventricular systolic pressure exceeding the right atrial pressure by $25 \mathrm{~mm}$ of Hg. Biventricular function was good with intact septum. There was no evidence of clot/effusion/aortic stenosis/aortic regurgitation or mitral regurgitation. The ejection fraction was $65 \%$.

Informed written consent was taken from the patient after explaining the anaesthetic plan and the risks involved. The anaesthetic plan was a saddle block spinal anaesthesia, taking into consideration the patient's insistence on retaining her consciousness intraoperatively, her previous successful experience with spinal anaesthesia, limited area of spinal block required, an anticipated difficult airway and absence of septal defects or cardiac failure.

On the preoperative day, the patient was given tablet alprazolam $0.5 \mathrm{mg}$ and tablet ranitidine $150 \mathrm{mg}$ at night and the following morning antihypertensive medication was continued. Infective endocarditis prophylaxis was given despite the low risk in the anomaly. $(3,4)$

The patient was shifted to the operation room, cockpit drill performed and difficult airway cart and emergency cart were both kept ready to tide over any untoward incidents. Continuous noninvasive blood pressure, peripheral arterial oxygen saturation and electrocardiography monitors were connected to the patient and the baseline readings were recorded. Basal heart rate and blood pressure was $88 /$ minute and $122 / 88 \mathrm{~mm}$ of $\mathrm{Hg}$ respectively. One wide bore peripheral intravenous line was secured and all measures were taken to prevent any air bubbles from entering through the IV cannulas. The patient was given subarachnoid block in anti-trendelenberg position in the L3-L4 interspace with a combination of bupivacaine $0.5 \%$ heavy $4.5 \mathrm{mg}$ and fentanyl $15 \mathrm{mcg}$ (Total volume of $1.2 \mathrm{ml}$ ) and was put in lithotomy position after 3 minutes.

There was good anaesthetization with sensory and motor blockade of the saddle area. The patient was haemodynamically stable, without hypotension, rhythm disturbances or any other untoward incident throughout the procedure which lasted for 40 minutes. At the end of the surgery the sensory and motor blockade was found to be confined to T12 level. The patient was then shifted to post anaesthesia care unit and was followed up for $48 \mathrm{hrs}$ without any untoward findings/occurances.

DISCUSSION: Congenital heart diseases (CHD), can be either cyanotic or acyanotic, complicate approximately $1 \%$ of all the live births in the general population and $4 \%$ of offsprings of women with CHD.(5) Ebstein's anomaly, which occurs in less than 1\% of all congenital heart defects and the most 


\section{ORIGINAL ARTICLE}

common cause of primary tricuspid regurgitation,(6) is an abnormality of the tricuspid valve. The valve has three leaflets: anterior, posterior and septal.

The anomaly is characterized by malformation of the tricuspid valve and the right ventricle in the form of- adherence of the septal and posterior leaflets to the underlying myocardium (Failure of delamination); downward (Apical) displacement of the functional annulus; dilation of the "Atrialized" portion of the right ventricle with various degrees of hypertrophy and thinning of the wall; redundancy, fenestrations and tethering of the anterior leaflet and dilation of the right atrioventricular junction (True tricuspid annulus). This results in the right ventricle being divided into 2 regions: the part directly involved with the malformation (i.e. the inlet portion), which is functionally integrated with the right atrium, and the part that is not involved in the anomaly which constitutes the functional right ventricle (i.e. the trabecular and the outlet portions).

The "Atrialized" portion of the right ventricle can become disproportionately dilated and may account for more than half of the right ventricular volume in extreme cases instead of the usual one third of the right ventricular volume. There is often a marked dilatation of the true tricuspid valve annulus, which is not displaced, and a large chamber (Atrialized portion of the right ventricle) separating this true annulus from the functional right ventricle.(3)

The functional impairment of the right ventricle and regurgitation of the tricuspid valve retard the forward flow of blood through the right side of the heart. The volume of ejected blood is further decreased by the atrialized portion of the right ventricle, which balloons out during the right atrial contraction and acts as a passive reservoir. The overall effect is the dilatation of the right atrium and increase in the size of an interatrial communication, when it is present. This leads to the typical ebstein's configuration of the cardiac silhouette on chest radiograph which consists of a globe shaped heart with a narrow waist similar to that seen in pericardial effusion.

However it may vary from being almost normal to the typical ebstein's configuration with a cardiothoracic ratio of more than 0.65 carrying a poor prognosis.(3) Hence the major concerns in anaesthetizing these patients include decreased cardiac output, septal defects, right to left shunting, arrhythmias including Wolff Parkinson White syndrome (In up-to 10-20\% of these patients), $(7,8)$ serious rhythm disturbances, other associated cardiac anomalies, congestive cardiac failure and sudden circulatory collapse. The diagnostic triad of WPW consists of a wide QRS complex associated with a relatively short PR interval and slurring of the initial part of the QRS (Delta wave), with the latter effect being due to aberrant activation of ventricular myocardium. The presence of a bypass tract may predispose to reentrant supraventricular tachyarrhythmias.(9)

There have been reports of general anaesthesia having been used for various surgeries such as abdominal hysterectomy and laparoscopic cholecystectomy using either propofol-ketamine, thiopentone or propofol respectively.(10,11)

The advantage of general anaesthesia is that hypotension is usually avoided and fluid balance is easier to control. However it may necessitate the use of additional induction agent due to prolonged accumulation within the enlarged right atrium.(8) Additionally efforts to prevent hypoxaemia are required to avoid the development of pulmonary hypertension which may lead to worsening of the right to left shunt when it is present. The stress response which may occur due to laryngoscopy and intubation may lead to worsening of the condition.

Graded epidural technique is being increasingly used which overcomes the disadvantages of general anaesthesia. Hypotension that may occur is better managed as it is usually not precipitous. 
Suarez et al reported a case of graded epidural anaesthesia being used for caesarean section in a patient with Ebstein's anomaly in whom hypotension was managed successfully with crystalloids and phenylephrine. (12) Chaterjee et al have also demonstrated the use of graded epidural anaesthesia successfully in a 20 year old lady posted for caesarean section.(13)

Misa et al have reported a case of a parturient with Ebstein's anomaly with WPW syndrome, in whom they have successfully administered epidural analgesia.(14)

Total intravenous anaesthesia has also been used for caesarean section in the above condition with propofol and remifentanil.(15)

The use of spinal anaesthesia in patients with Ebstein's anomaly is largely limited due to the sympathetic blockade induced precipitous fall in blood pressure that may worsen the right to left shunt. Also arrhythmias that may occur is poorly tolerated by the ventricles.(16) Administration of intravenous fluids requires a cautious approach so as not to overload the circulation and hence prevent the development of congestive cardiac failure.(17) Introduction of central venous catheters is also associated with technical difficulty and precipitation of arrhythmias.(12)

Reports of subarachnoid block being used in patients with Ebsteins anomaly are scarce. We could come across one such report where a pregnant patient at 19 weeks post gestational age posted for medical termination of pregnancy and tubal ligation was successfully managed with combined spinal epidural anaesthesia, without any untoward intraoperative haemodynamic complications.(18)

Our patient gave a history of a good tolerance of subarachnoid blockade for her previous surgery, which followed two previous successful pregnancies with normal deliveries. She had an associated Wolff Parkinson White syndrome, but no additional serious conditions like septal defects with reversal of flow or cardiac failure. As she was posted for haemorrhoidectomy, we considered giving a low dose saddle block because of the reasons elaborated earlier. The lower dose was administered in view of the site of surgery and to minimize the sympathetic blockade.

CONCLUSION: A thorough understanding of the pathophysiology of the condition is essential for the successful anaesthetic management in patients with Ebstein's anomaly and the anaesthetic technique chosen should be individualized based on the cardiac status, type of surgery, site of surgery and also the duration of surgery. Our experience shows that, a low dose subarachnoid block may be considered as one of the options available to the anaesthesiologist in selected patients with Ebstein's anomaly for perineal surgeries of short to medium duration.

\section{REFERENCES:}

1. Mann R J, Lie J T. The story of Wilhelm Ebstein (1836- 1912) and his almost overlooked description of a congenital heart disease. Mayo Clin Proc 1979; 54: 197-203.

2. Franco S A, Hines R L. Congenital heart diseases. In Hines R L, Marschall K E (Ed). Stoelting's anaesthesia and co-existing disease. $6^{\text {th }}$ edition. China: Saunders Elseveir; 2012. 48-72.

3. Attenhofer Jost C H, Connolly H M, Dearani J A, Edwards W D, Danielson G K. Ebstein's Anomaly. Circulation 2007; 115: 277-285.

4. Nishimura RA, Otto CM, Bonow RO, et al. 2014 AHA/ACC guideline for the management of patients with valvular heart disease: a report of the American College of Cardiology/American Heart Association Task Force on Practice Guidelines. J Am Coll Cardiol 2014; 63: e57. 


\section{ORIGINAL ARTICLE}

5. Child J S, Aboulhosn J. Congenital heart disease in adult. In Longo D L, Kasper D L, Jameson J L, Fauci A S, Hauser S L, Loscalzo J (Ed). Harrison's principles of internal medicine. $18^{\text {th }}$ edition. Volume 2. United States of America: Mc Graw Hill; 2012. 1920-8.

6. Kaplan J A. Kaplan's Cardiac Anaesthesia: The ECHO Era.6th edition. Chapter 20: 622-3.

7. Gologorsky E, Patel N D, Govindaswamy R, Gologorsky A, Barron M E. Ebstein Anomaly of the Tricuspid Valve, Atrial Septal Defect, and Severe Right Ventricular Dysfunction in an adult: Transesophageal Echocardiographic Images. Anaesthesia Analgesia 2010; 110(3): Pg 719-21.

8. Groves E R. Epidural analgesia for labour in a patient with Ebstein's anomaly; Can J Anaesth 1995; 42(1): 77-9.

9. Goldberger A L. Electrocardiography. In Longo D L, Kasper D L, Jameson J L, Fauci A S, Hauser S L, Loscalzo J (Ed). Harrison's principles of internal medicine. 18 th edition. Volume 2. United States of America: Mc Graw Hill; 2012.1831-9.

10. Khatib S K, Tadwalkar G V. Case report: Anaesthetic implications of Ebstein's anomaly. Anaesth Pain \& Intensive Care 2012; 16(1): 60-3.

11. Chaudhuri A H, Uppal R, Khaitan M. Laparoscopic cholecystectomy in a patient with Ebstein's anomaly: Anaesthetic consideration. Saudi J Anaesth 2012; 6(3): 301-2.

12. Suarez O H, Acero L R V, Hernandez J A V. Epidural anaesthesia for caesarean section in a patient with Ebstein's Anomaly. Rev Colomb Anaesthesiol 2011; 39(2).

13. Chaterjee S, Sengupta I, Mandal R, Sarkar R, Chakraborty P S. Anaesthetic management of Caesarean section in a patient with Ebstein's anomanly. Indian Journal of Anaesthesiology 2008; 52(3): 321-3.

14. Misa S, Pan P H. Evidence based case report for analgesia and anaesthetic management of a parturient with Ebstein's anomaly with WPW syndrome. Int J obst Anaesth 2007; 16(1): 77-81.

15. Marfarlane A J, Moise S, Smith D. Caesarean section using total intravenous anaesthesia in a patient with Ebstein's anomaly complicated by supraventricular tachycardia. Int $\mathrm{j}$ Obstet Anesth 2007; 16(2): 155-9.

16. Loomba R S, Chandrasekhar S, et al. Association of atrial tachyarrhythmias with Atrial Septal Dfects, Ebstein's anomaly and fontan patient. Expert Rev Cardivasc Ther 2011; 9(7): 887-93.

17. Sushma K S, Shaikh S, Ashwini H R. Anaesthetic management of a parturient with Ebstein's anomaly. Journal of Obstetric Anaesthesia and Critical Care 2013; 3(2): 101-3.

18. Selvaraj B J, Baidya DK, Khanna P. A patient of bad obstetric history with ebstein's anomaly: perianesthetic concerns. Anesth Essays and Res 2013; 7: 288-9. 


\section{ORIGINAL ARTICLE}
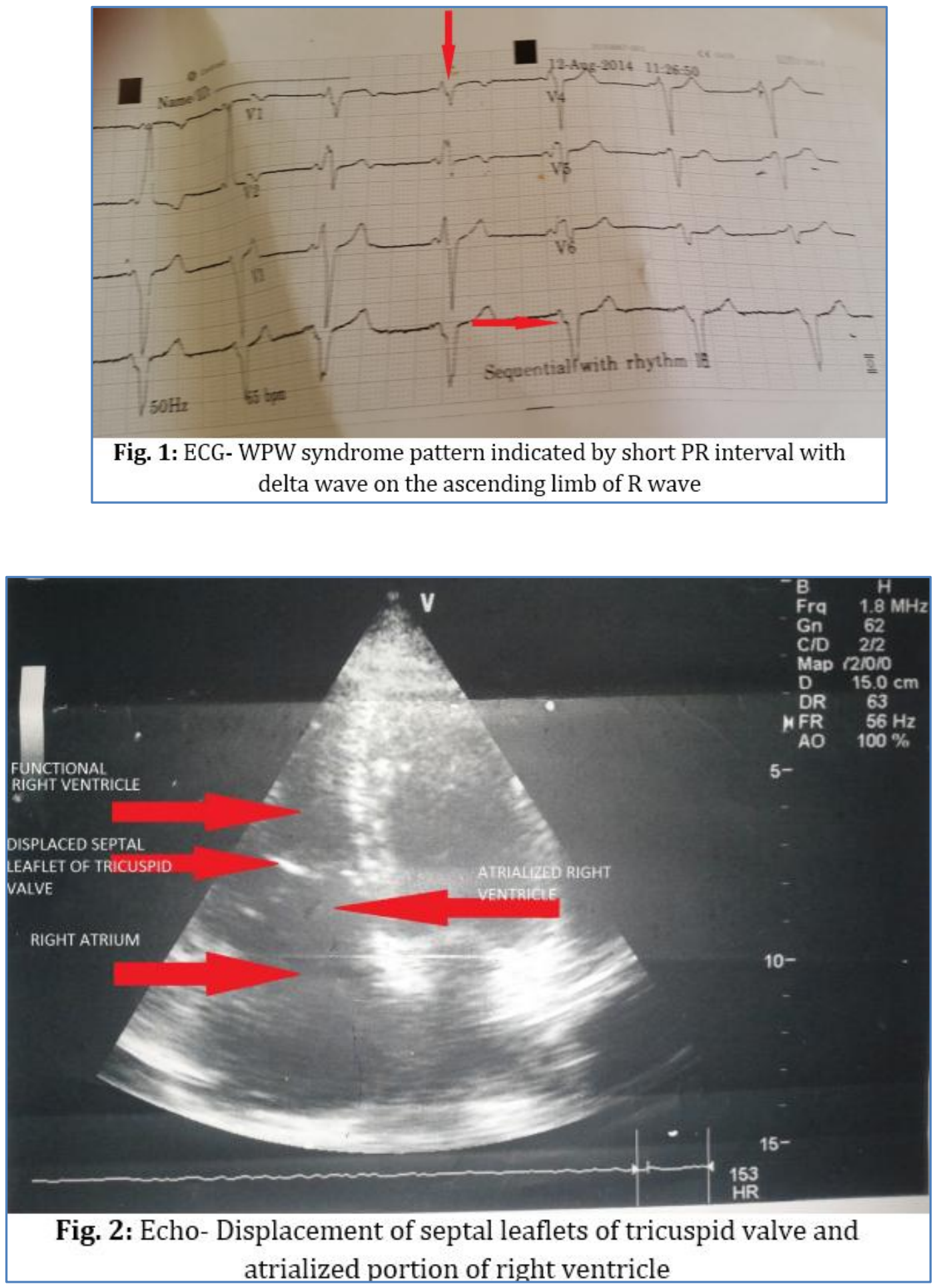


\section{ORIGINAL ARTICLE}

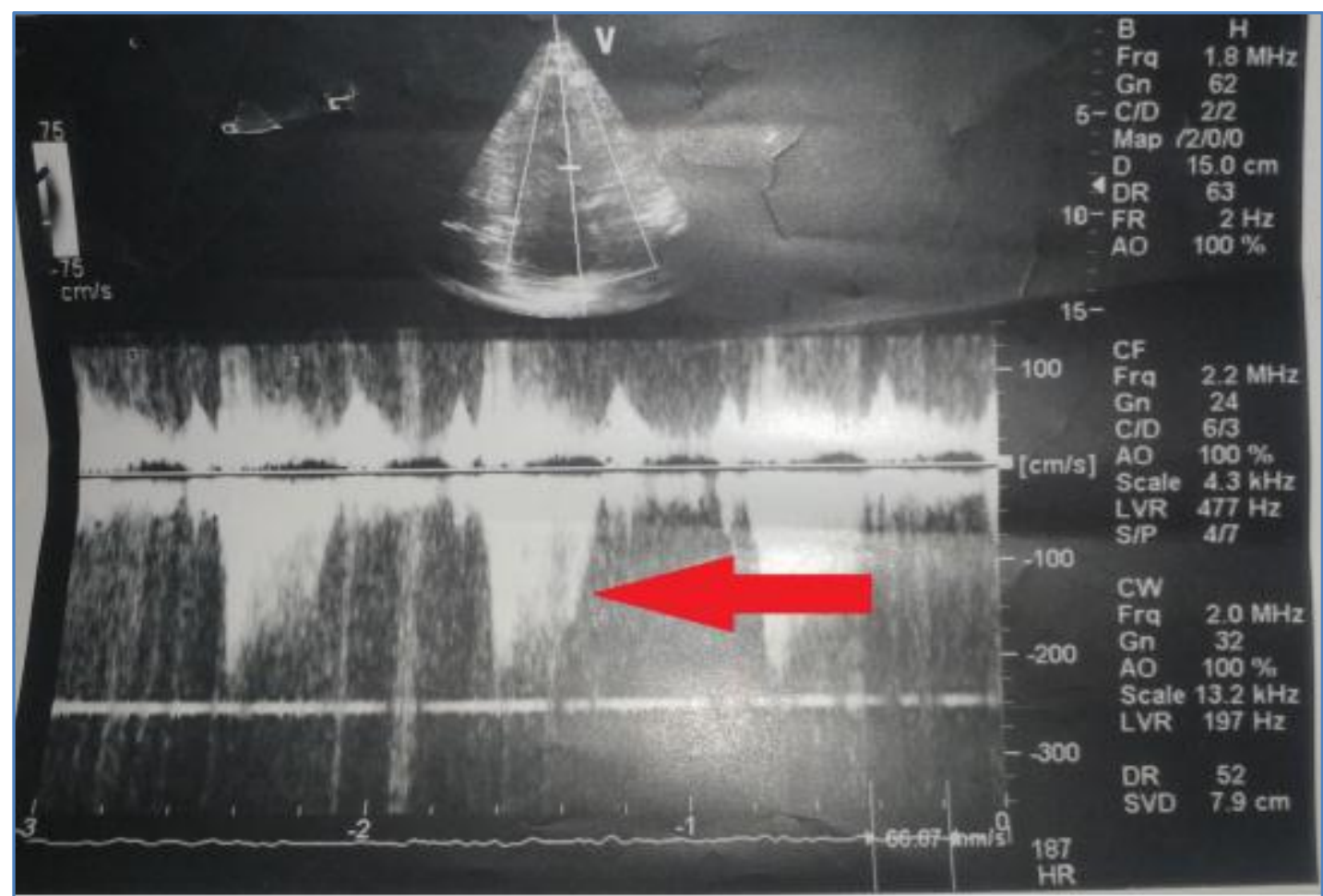

Fig. 3: Echo- Spectral pattern across tricuspid valve showing TR jet

\section{AUTHORS:}

1. Usha Devi R.

2. Vasantha kumar K. R.

3. Vasundhara V. M.

4. Aditi Prabhu

\section{PARTICULARS OF CONTRIBUTORS:}

1. Associate Professor, Department of Anaesthesiology, Adichunchanagiri Institute of Medical Sciences, Bellur, Mandya.

2. Professor, Department of Anaesthesiology, Adichunchanagiri Institute of Medical Sciences, Bellur, Mandya.

\section{FINANCIAL OR OTHER}

COMPETING INTERESTS: None
3. Junior Resident, Department of Anaesthesiology, Adichunchanagiri Institute of Medical Sciences, Bellur, Mandya.

4. Junior Resident, Department of Anaesthesiology, Adichunchanagiri Institute of Medical Sciences, Bellur, Mandya.

\section{NAME ADDRESS EMAIL ID OF THE CORRESPONDING AUTHOR:}

Dr. Usha Devi R,

No. $4,5^{\text {th }}$ Main, Yadavagiri,

Mysore-570020,

Karnataka.

E-mail: ushadevi_ramaiah@rediffmail.com

Date of Submission: 09/09/2015.

Date of Peer Review: 10/09/2015.

Date of Acceptance: 01/10/2015.

Date of Publishing: 12/10/2015. 